Tạp chí Khoa học và Công nghệ biển T10 (2010). Số 3. Tr 77 - 87

\title{
SỰ THAY ĐỔI CỦA QUẦn XÃ CÁ RẠN THEO CÁC KIỂU HİNH THÁI RẠN SAN HÔ
}

\author{
NGUYẼ̃N VĂN LONG
}

Viện Hải dương học

\begin{abstract}
Tóm tắt: Nghiên cứu sụ thay đổi của quần xã cá rạn theo các kiểu hình thái rạn san hô đuợc thưc hiện tại 60 mặt cắt tại 3 rạn dạng riềm điển hình, 3 rạn riềm không điển hình và 3 rạn kiểu dạng nền tại khu vục vịnh Cà Ná, vùng biển ven bờ Nam Trung bộ trong năm 2005 và 2006. Kết quả phân tích nhóm và đa chiều dựa vào thành phần loài và mức độ phong phú của quần xã cá rạn giũa 3 kiểu rạn cho thấy có sư hình thành riêng biệt giũa 2 tập hợp của quần xã cá rạn dạng nền và rạn dạng riềm điển hình $(P<0,01)$ và giữa rạn dạng nền và rạn dạng riềm không điển hình $(P<0,01)$, nhưng không có sụ khác nhau giữa rạn dạng riềm điển hình và không điển hình $(P>0,05)$. Rạn dạng nền có độ giàu có về loài và mật độ cá thể trung bình $\left(25,1\right.$ loài/100m và 127,0 con $\left./ 100 \mathrm{~m}^{2}\right)$ cao hơn nhiều so với rạn dạng riềm điển hình $\left(14,4\right.$ loài $/ 100 m^{2}$ và 94,8 con/100m $\left.{ }^{2}\right)$ và không điển hình $\left(13,2\right.$ loài $/ 100 m^{2}$ và 75,9 con $\left./ 100 \mathrm{~m}^{2}\right)$, trong khi đó các giá trị này lại khá tương đồng giữa rạn riềm điển hình và không điển hình. Hệ số tuơng quan giữa rạn dạng riềm điển hình và riềm không điển hình khá thấp $(R=0,469)$, nhung chi số này lại cao hơn nhiều khi so sánh giũa rạn dạng nền với rạn dạng riềm điển hình $(R=0,897)$ và với rạn dạng riềm không điển hình có giá trị khá thấp $(R=$ 0,925). Điều này cho thấy rằng tính chất quần xã cá rạn của kiểu rạn riềm điển hình và không điển hình khá tuơng đồng, nhung lại có sự khác biệt giũa rạn dạng nền với dạng rạn riềm điển hình và không điển hình.
\end{abstract}

\section{MỞ ĐÀ̀}

Mặc dù đã có một số công trình nghiên cứu liên quan đến sự hình thành các dạng tập hợp quần xã cá rạn theo cấu trúc rạn san hô, nhưng cho đến nay những nghiên cứu chi tiết về tính chất và cấu trúc của quần xã cá rạn theo hình thái và cấu trúc rạn là rất ít. Kết quả của một số nghiên cứu cho rằng hình thái và cấu trúc phức tạp của rạn sẽ ảnh hưởng đến thành phần loài và sự phong phú của cá rạn (Beukers và Jones, 1997). Sự đa dạng, phân bố và mức độ phong phú của cá rạn chịu sự chi phối bởi thành phần cấu trúc của quần cư (Steele, 1999; McClanahan và Arthur, 2001). Galzin và Legendre (1987) xác định 4 kiểu tập hợp quần xã cá rạn san hô ở khu vực Polynesia (Pháp) và cho rằng chúng có liên quan mật thiết đối với sự khác nhau về cấu trúc hình thái của các kiểu rạn như rạn riềm, lagun, mặt bằng rạn và sườn dốc rạn bên ngoài. Letourneur (1996a) nghiên cứu quần xã cá rạn ở 
vùng đảo Reunion cũng đã xác định 3 kiểu tập hợp quần xã cá rạn phân bố theo các đới khác nhau.

Gladfelter và Gladfelter (1978) khi nghiên cứu cấu trúc quần xã cá rạn trong các lagun ở quần đảo Virgin - Australia cho rằng sự thay đổi cấu trúc quần xã cá rạn có liên quan đến sự khác nhau của cấu trúc quần cư. Galzin (1987) đã ghi nhận sự đồng nhất về các tập hợp thành phần loài cá rạn ở độ sâu 3 - $30 \mathrm{~m}$ khu vực đảo Moore - Polynesia (Pháp). Ở các rạn khu vực Tulear (Madagascar), Harmelin-Vivien (1977) xác định 2 kiểu quần xã riêng biệt trên các đới nông và sâu $>20 \mathrm{~m}$ của rạn san hô. Letourneur và cộng sự (2000) ghi nhận phân bố của quần xã cá rạn san hô không có sự đồng nhất giữa 3 kiểu rạn (rạn chắn, rạn nền và rạn riềm) ở vùng biển New Caledonia, trong đó vùng rạn chắn có sinh khối và trữ lượng cao hơn so với vùng rạn dạng nền và rạn dạng riềm.

Vùng biển ven bờ vịnh Cà Ná được ghi nhận có sự tồn tại của 3 kiểu dạng hình thái và cấu trúc là rạn dạng riềm điển hình (fringing reef), rạn riềm không điển hình (nonfringing reef) và rạn dạng nền (platfom reef) (Võ Sĩ Tuấn và cộng sự, 2005). Do sự khác biệt về lịch sử hình thành và phát triển cũng như về hình thái và cấu trúc nên tính chất khu hệ san hô tạo rạn cũng có sự khác nhau giữa các kiểu dạng rạn nói trên. Vấn đề được đặt ra là liệu sự khác biệt về hình thái và cấu trúc giữa các kiểu rạn có tạo nên sự khác biệt về tính chất của quần xã cá rạn hay không thì vẫn chưa được quan tâm nghiên cứu. Bên cạnh đó, khu vực vịnh Cà Ná đang được xem là một trong 15 khu vực quan trọng đề xuất được thiết lập khu bảo tồn biển trong hệ thống khu bảo tồn biển Việt Nam. Vì vậy, các kết quả của nghiên cứu này sẽ góp phần nâng cao sự hiểu biết về tính chất và cấu trúc của quần xã cá rạn giữa các kiểu hình thái rạn nói trên, đồng thời cung cấp những tư liệu cần thiết phục vụ cho việc quy hoạch bảo tồn biển tại khu vực này trong tương lai.

\section{TÀI LIỆU VÀ PHƯƠNG PHÁP}

\section{Thời gian và địa điểm}

Các chuyến điều tra thu thập số liệu được thực hiện tại 9 điểm rạn trong vịnh Cà Ná vào tháng 6 năm 2005 và tháng 10 năm 2006. Trong đó, 3 điểm đại diện cho rạn dạng nền (bãi rạn ngầm Breda), 3 điểm rạn dạng riềm điển hình (phía Bắc Cù Lao Cau) và 3 điểm rạn dạng riềm không điển hình (phía Đông và Đông Nam Cù Lao Cau) (hình 1). 


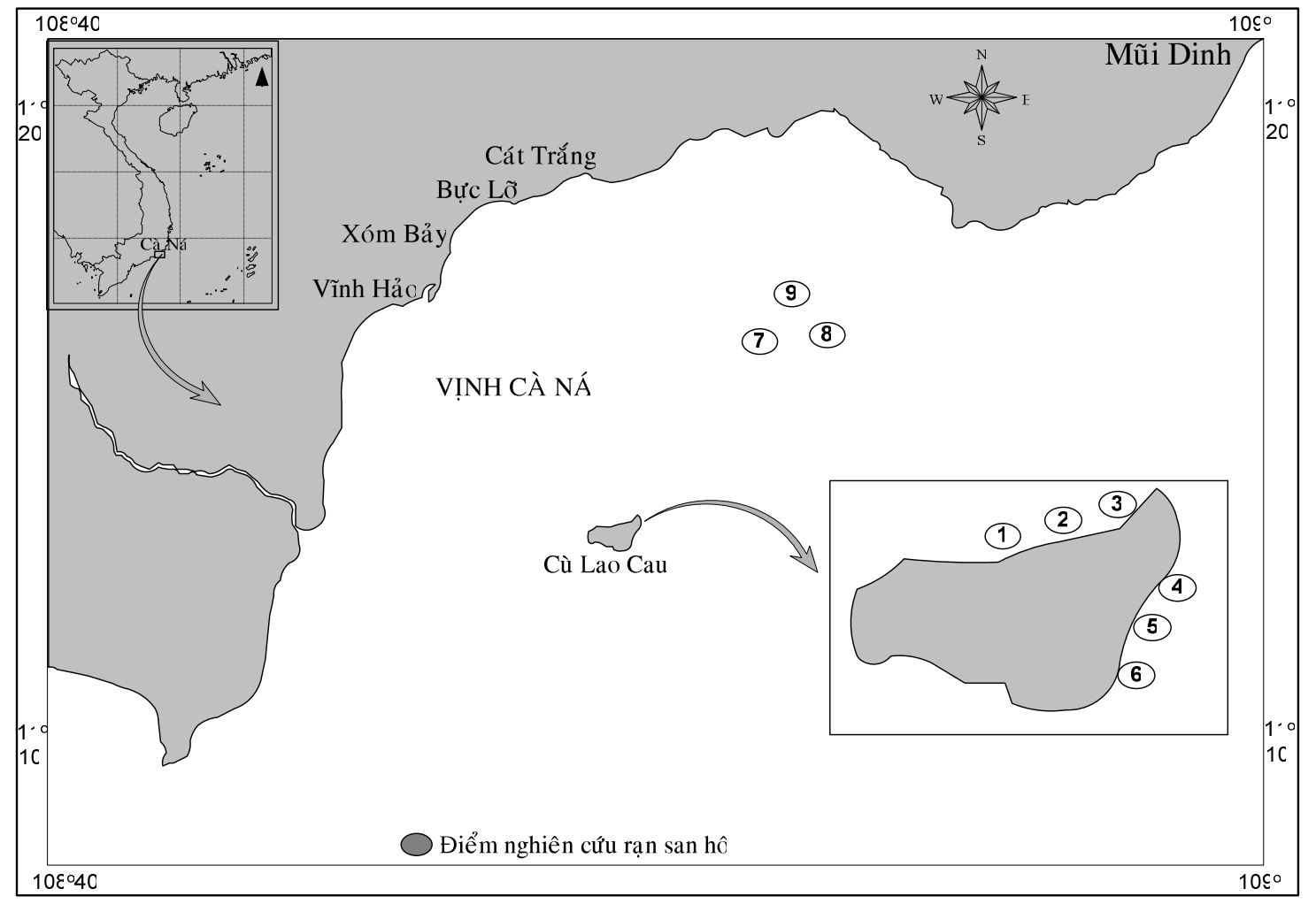

Hình 1: Vị trí các điểm nghiên cứu trong vịnh Cà Ná. Chú thích: điểm 1, 2, 3 đại diện cho kiểu rạn riềm điển hình (fringing reef); điểm 4, 5, 6 đại diện cho kiểu rạn riềm không điển hình (non-fringing reef) và điểm 7, 8, 9 đại diện cho kiển rạn dạng nền (platform reef) trên bãi cạn Breda

\section{Phương pháp thu thập số liệu}

Tại mỗi rạn khảo sát đã được chọn lựa của rạn dạng riềm điển hình và không điển hình, hai dây mặt cắt có độ dài mỗi dây $100 \mathrm{~m}$ được rải song song với bờ trên hai đới mặt bằng (độ sâu từ $2-5 \mathrm{~m}$ ) và sườn dốc (từ $6-12 \mathrm{~m}$ ) tùy thuộc vào địa hình của mỗi điểm rạn khảo sát. Trên mỗi dây mặt cắt của từng đới rạn được chia thành 4 đoạn, mỗi đoạn có chiều dài $20 \mathrm{~m}$ và hai đoạn cách nhau $5 \mathrm{~m}$. Tại mỗi điểm có 8 đoạn mặt cắt (4 trên mặt bằng và 4 trên sườn dốc rạn) được thu thập số liệu, và đây được xem là mẫu lập lại khi phân tích thống kê. Riêng đối với 3 điểm rạn dạng nền trên bãi cạn Breda, do cấu trúc địa hình khá tương tự nhau và không có sự phân chia thành các đới rõ ràng (mặt bằng và sườn dốc) nên mỗi điểm chỉ được khảo sát trên 1 đới mặt bằng rạn (độ sâu $3-4 \mathrm{~m}$ ) gồm 4 đoạn mặt cắt. Như vậy, tổng số có 60 đoạn mặt cắt tại 9 điểm rạn được khảo sát (24 mặt cắt tại 3 rạn dạng riềm điển hình, 24 đoạn mặt cắt tại 3 rạn dạng riềm không điển hình và 12 đoạn mặt cắt tại 3 rạn dạng nền). 
Sau khi mặt cắt đã được cố định khoảng 15 phút, người quan sát cá tiến hành bơi chậm dọc theo dây mặt cắt, đếm số lượng cá thể và kích thước (chiều dài thân) của từng loài cá rạn trong phạm vi diện tích của mỗi đoạn mặt cắt là $100 \mathrm{~m}^{2}(20 \mathrm{~m}$ dài và $5 \mathrm{~m}$ rộng) theo phương pháp của English và cộng sự (1997), Hodgson và Waddell (1998). Việc định loại cá rạn được dựa theo các tài liệu phân loại hiện hành của Carcasson (1977), Randall và cộng sự (1990), Myers (1991), Kuiter (1992), Allen và cộng sự (2003).

\section{Xử lý và phân tích số liệu}

Các tập hợp quần xã cá rạn đặc trưng được thực hiện bằng phương pháp phân tích nhóm (cluster analysis) và phân tích đa chiều (multidimension scaling - MDS) dựa vào thành phần loài và sự phong phú của quần xã cá rạn. So sánh sự khác biệt giữa các tập hợp quần xã cá rạn được thực hiện bằng phép thử thống kê sự giống nhau giữa các tập hợp (ANOSIM randomization test; Clarke, 1993). Xác định các nhóm loài đặc trưng cho các dạng tập hợp quần xã cá rạn được thực hiện bằng phép tính SIMPER. Các phép phân tích này được thực hiện trên phần mềm PRIMER 5.0. So sánh sự sai khác về độ giàu có loài và mật độ của quần xã cá rạn giữa các dạng rạn để thực hiện bằng phép thử thống kê một biến (One-way ANOVA). Để giảm thiểu tính không đồng nhất, số liệu độ giàu có loài và mật độ của quần xã cá rạn được chuyển dạng bằng cách lấy logarit của các giá trị này $(\log (\mathrm{x}+1))$ trước khi thực hiện các phép thử thống kê.

\section{KẾT QUẢ VÀ THẢO LUẬN}

Kết quả phân tích nhóm và đa chiều sự phong phú của quần xã cá rạn san hô của các khu vực rạn đại diện cho 3 kiểu hình thái rạn (dạng riềm điển hình, dạng riềm không điển hình và dạng nền) ở vịnh Cà Ná cho thấy có sự hình thành 2 tập hợp quần xã cá rạn riêng biệt đặc trưng cho nhóm rạn dạng nền và nhóm rạn dạng riềm (gồm rạn riềm điển hình và riềm không điển hình) (hình 2 và 3 ).

Các kết quả phép thử thống kê về sự giống nhau giữa các tập hợp quần xã cá rạn (ANOSIM test) theo các dạng hình thái rạn san hô cho thấy có sự khác nhau rõ ràng giữa 2 tập hợp của quần xã cá rạn dạng rạn nền và dạng rạn riềm $(\mathrm{P}<0,01)$ và giữa rạn dạng nền và dạng rạn riềm không điển hình $(\mathrm{P}<0,01)$, trong khi đó không có sự khác nhau giữa dạng rạn riềm điển hình và không điển hình $(\mathrm{P}>0,05)$ (bảng 1$)$. Hệ số tương quan (Global $\mathrm{R}$ ) giữa các tập hợp kiểu dạng rạn riềm điển hình và không điển hình có giá trị khá thấp đối $(\mathrm{R}$ $=0,469)$, trong khi đó chỉ số này lại có giá trị cao khi so sánh giữa nhóm rạn dạng riềm điển hình và dạng rạn nền $(\mathrm{R}=0,897)$, giữa rạn dạng riềm không điển hình và dạng rạn nền $(\mathrm{R}=$ 0,925) (Bảng 1). Điều này cho thấy rằng tính chất quần xã cá rạn của kiểu rạn riềm điển hình và không điển hình khá tương đồng nhưng lại khác biệt so với kiểu dạng rạn nền. 


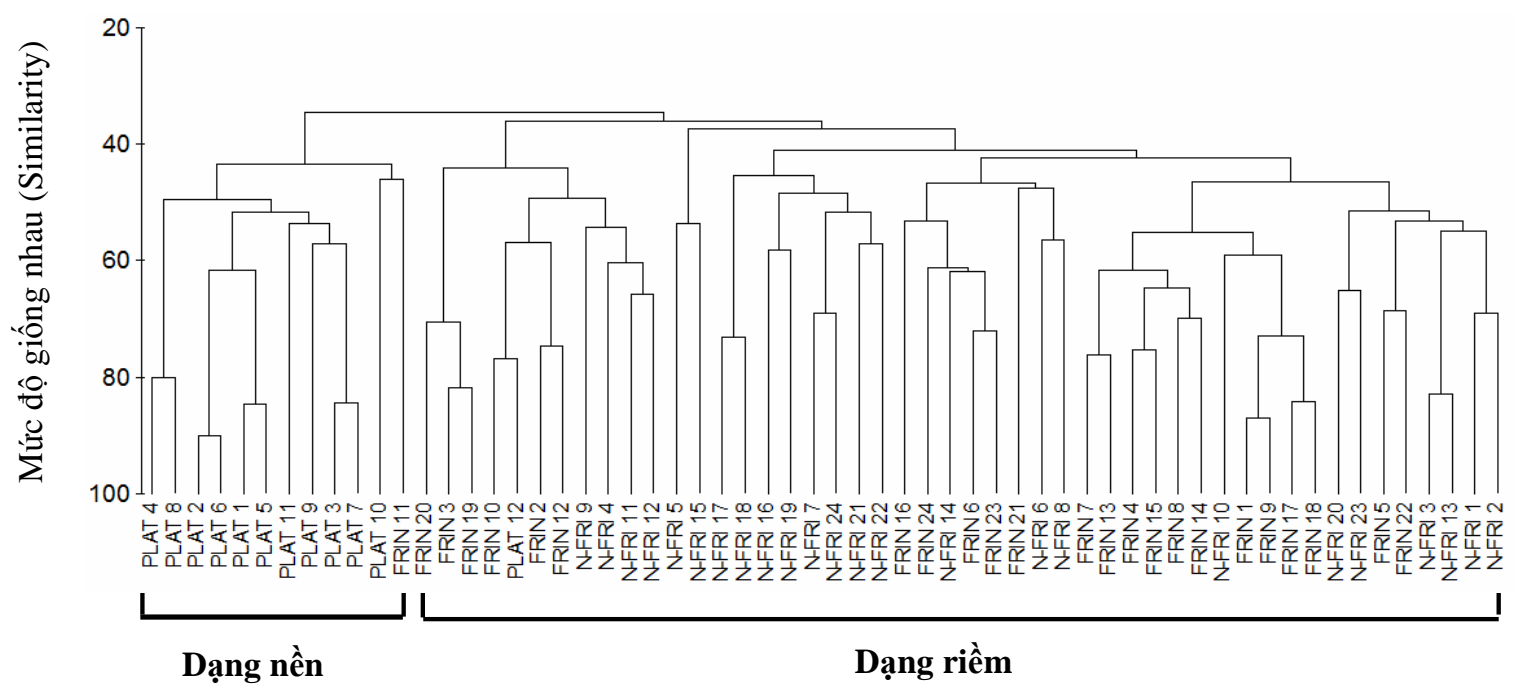

Hình 2: Sự hình thành các dạng tập hợp quần xã cá rạn san hô trên cơ sở kết quả phân tích nhóm về sự phong phú cá rạn theo các dạng hình thái rạn san hô. Chú thích: FRIN: Rạn riềm điển hình; N-FRIN: Rạn riềm không điển hình; PLAT: Rạn dạng nền

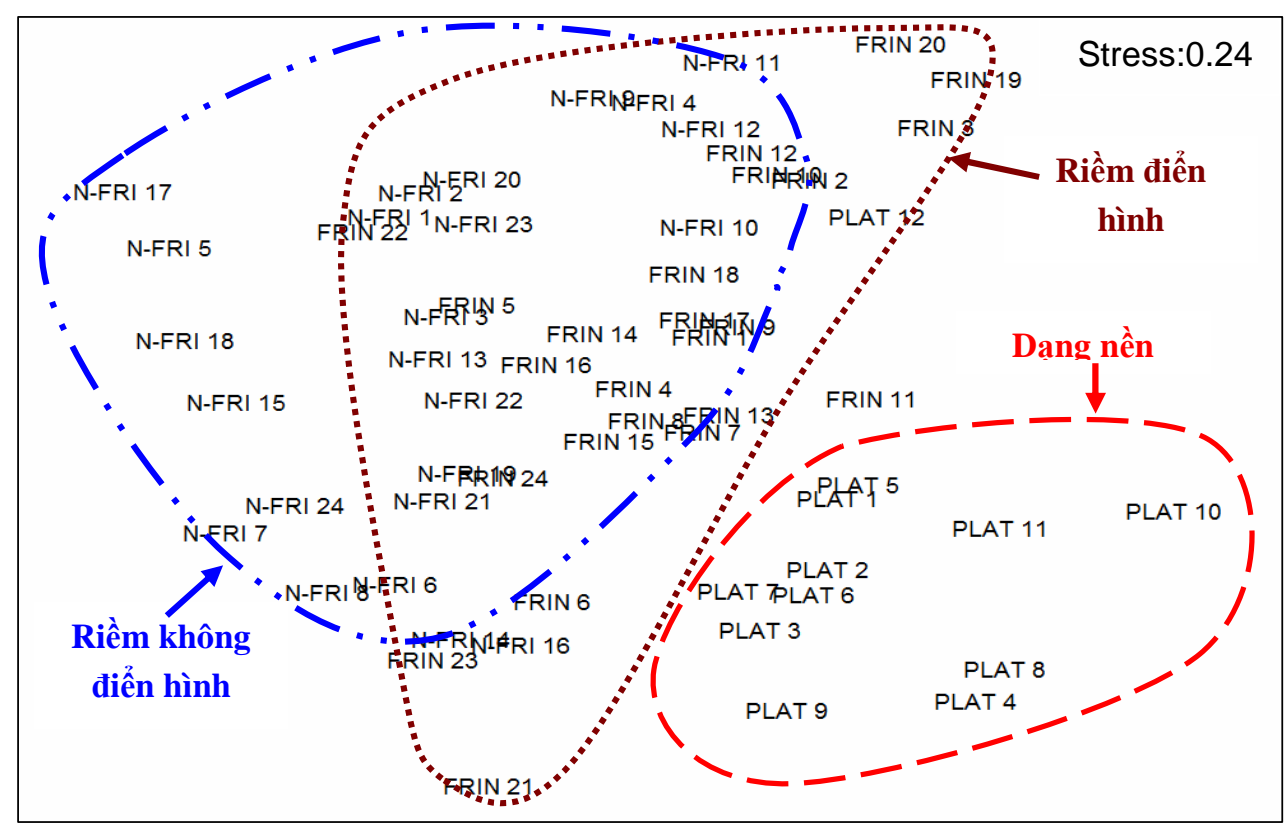

Hình 3: Sự hình thành các dạng tập hợp quần xã cá rạn san hô từ kết quả phân tích đa chiều về sự phong phú cá rạn theo các dạng hình thái rạn san hô. Chú thích: FRIN: Rạn riềm điển hình; N-FRIN: Rạn riềm không điển hình; PLAT: Rạn dạng nền 
Bảng 1: Tóm tắt kết quả thống kê sự giống nhau giữa các tập hợp quần xã cá rạn theo kiểu hình thái rạn san hô trong vịnh Cà Ná.

Số trong ngoặc biểu thị hệ số tương quan R. *: P <0,05

\begin{tabular}{|c|c|c|}
\hline & Rạn dạng nền & Rạn riềm điển hình \\
\hline Rạn riềm điển hình & $0,001(0,897)^{*}$ & \\
\hline Rạn riềm không điển hình & $0,002(0,925)^{*}$ & $0,0587(0,469)$ \\
\hline
\end{tabular}

So sánh mức độ giàu có về loài và mật độ của quần xã cá rạn theo các dạng hình thái rạn cho thấy độ giàu có về loài của dạng rạn riềm điển hình (trung bình 14,4 loài/100 $\mathrm{m}^{2}$ ) khá tương đồng với dạng rạn riềm không điển hình $\left(13,2\right.$ loài/100 $\left.\mathrm{m}^{2}\right)$, nhưng lại thấp hơn nhiều so với rạn dạng nền $\left(25,1\right.$ loài/100 $\left.\mathrm{m}^{2}\right)$ (bảng 2). Đối với mật độ cũng phản ánh một xu thế tương tự là rạn riềm điển hình có mật độ trung bình $\left(94,8\right.$ con/100 $\left.\mathrm{m}^{2}\right)$ cao hơn đôi chút so với rạn riềm không điển hình $(75,9$ con/100 m²), nhưng lại thấp hơn đáng kể so với rạn dạng nền $(127,0$ con/100 m²) (bảng 2).

Bảng 2: So sánh độ giàu có về loài (loài/100 m²) và mật độ (con/100 m²) giữa các dạng hình thái rạn san hô ở vịnh Cà Ná

\begin{tabular}{|c|c|c|c|c|c|c|}
\hline $\begin{array}{c}\text { Các đặc } \\
\text { trưng }\end{array}$ & \multicolumn{2}{|c|}{$\begin{array}{c}\text { Riềm điển } \\
\text { hình }\end{array}$} & \multicolumn{2}{c|}{$\begin{array}{c}\text { Riềm không điển } \\
\text { hình }\end{array}$} & \multicolumn{2}{c|}{ Dạng nền } \\
\hline & Dao động & Trung bình & Dao động & Trung bình & Dao động & Trung bình \\
\hline $\begin{array}{c}\text { Độ giàu có } \\
\text { về loài }\end{array}$ & $5-26$ & $14,4 \pm 1,2$ & $3-23$ & $13,2 \pm 1,1$ & $16-40$ & $25,1 \pm 1,9$ \\
\hline Mật độ & $14-219$ & $94,8 \pm 10,7$ & $27-159$ & $75,9 \pm 8,2$ & $69-206$ & $\begin{array}{c}127,0 \pm \\
12,4\end{array}$ \\
\hline
\end{tabular}

Kết quả của các phép thử thống kê phản ảnh sự khác nhau rõ ràng độ giàu có về loài $(\mathrm{P}<0,001)$ và mật độ $(\mathrm{P}<0,05)$ của cá rạn giữa rạn dạng nền và rạn riềm. Nếu chấp nhận giả thuyết mức độ ảnh hưởng của hoạt động khai thác trong khu vực là giống nhau. Điều này cho phép khẳng định rằng có sự khác nhau giữa quần xã cá rạn san hô của rạn dạng nền và rạn riềm, trong đó độ giàu có và phong phú của quần xã cá rạn thuộc rạn dạng nền cao hơn so với rạn dạng riềm. Thành phần loài, mật độ và tần số xuất hiện của các nhóm loài đặc trưng tạo nên sự khác biệt trong cấu trúc của các dạng tập hợp quần xã cá rạn được liệt kê trong bảng 3 . 
Bảng 3: Các nhóm loài đặc trưng cho từng kiểu quần xã cá rạn san hô ở các vùng biển Việt Nam. Chú thích: TA: Tổng số cá thể đếm được; MD: Mật độ trung bình (con/100 m²); F: Tần số suất hiện trong nhóm.

\begin{tabular}{|c|c|c|c|c|c|}
\hline Họ & Loài & TA & $\%$ & MD & $\mathbf{F}$ \\
\hline \multicolumn{6}{|c|}{ Rạn dạng nền } \\
\hline Pomacentridae & Chromis viridis & 1.525 & 45,7 & 127,1 & 3 \\
\hline Pomacentridae & Pomacentrus sp & 317 & 9,5 & 26,4 & 8 \\
\hline Pomacentridae & Neoglyphidodon melas & 199 & 6,0 & 16,6 & 12 \\
\hline Pomacentridae & Dascyllus reticulatus & 107 & 3,2 & 8,9 & 8 \\
\hline Pomacentridae & Pomacentrus burroughi & 87 & 2,6 & 7,3 & 6 \\
\hline Pomacentridae & Amblyglyphidodon curacao & 76 & 2,3 & 6,3 & 9 \\
\hline Chaetodontidae & Chaetodon trifascialis & 57 & 1,7 & 4,8 & 12 \\
\hline Apogonidae & Apogon spl & 50 & 1,5 & 4,2 & 3 \\
\hline Pomacentridae & Hemiglyphidodon plagiometopon & 35 & 1,0 & 2,9 & 7 \\
\hline Pempheriidae & Pempheris oualensis & 30 & 0,9 & 2,5 & 2 \\
\hline Acanthuridae & Ctenochaetus strigosus & 23 & 0,7 & 1,9 & 4 \\
\hline & Tổng & 2.506 & 75,2 & & \\
\hline & g (tất cả các loài) & 3.334 & & & \\
\hline \multicolumn{6}{|c|}{ Rạn dạng riềm (điển hình và không điển hình) } \\
\hline Pomacentridae & Pomacentrus chrysurus & 1.099 & 23,9 & 22,9 & 43 \\
\hline Apogonidae & Apogon sealei & 187 & 4,1 & 3,9 & 9 \\
\hline Labridae & Thalassoma lunare & 176 & 3,8 & 3,7 & 33 \\
\hline Pomacentridae & Pomacentrus moluccensis & 169 & 3,7 & 3,5 & 22 \\
\hline Scaridae & Scarus sordidus & 164 & 3,6 & 3,4 & 15 \\
\hline Pomacentridae & Abudefduf sexfasciatus & 121 & 2,6 & 2,5 & 9 \\
\hline Pomacentridae & Neoglyphidodon nigrogris & 104 & 2,3 & 2,2 & 26 \\
\hline Labridae & Thalassoma hardwicke & 89 & 1,9 & 1,9 & 13 \\
\hline & Tổng & 2.109 & 45,8 & & \\
\hline \multicolumn{2}{|c|}{ Tổng (tất cả các loài) } & 4.602 & & & \\
\hline
\end{tabular}


Sự hình thành 2 tập hợp quần xã cá rạn đặc trưng cho rạn dạng riềm và rạn dạng nền cho thấy tính chất thành phần và cấu trúc quần xã cá rạn chịu sự chi phối bởi thành phần và cấu trúc của nền đáy rạn san hô trong từng kiểu rạn. Võ Sĩ Tuấn và cộng sự (2005) cho rằng có sự khác biệt về thành phần san hô giữa các rạn dạng riềm và rạn dạng nền trong khu vực vịnh Cà Ná. Quần xã san hô rạn dạng nền của bãi cạn Breda chủ yếu là san hô mềm Sarcophyton với sự xen kẽ với một số san hô cứng dạng khối thuộc giống Goniastrea, Porites, Platygyra và rong mơ Sargassum. Các rạn dạng riềm ở khu vực đảo Cù Lao Cau lại ưu thế bởi các thảm đơn loài thuộc giống san hô cứng Montipora, Panova, Acropora, Favia, Cyphastrea, Physogyra, Turbinaria và Pachyseris.

Sự khác nhau về thành phần và cấu trúc các dạng hợp phần nền đáy rạn nói trên có thể là yếu tố tạo nên sự khác biệt giữa hai tập hợp quần xã cá rạn giữa rạn dạng riềm và rạn dạng nền. Sự khác biệt không đáng kể về hình thái và cấu trúc giữa dạng rạn riềm điển hình và không điển hình (Võ Sĩ Tuấn và cộng sự, 2005) có thể tạo nên sự tương đồng về tính chất phân bố và cấu trúc của quần xã cá rạn giữa hai dạng rạn này. Các nghiên cứu đã chỉ ra rằng độ phủ san hô sống (Carpenter và cộng sự, 1981; Bell và Galzin, 1984; Cadoret và cộng sự, 1999; Nguyen Van Long và Phan Kim Hoang, 2008), thành phần và cấu trúc quần xã (Steele, 1999; McClanahan và Arthur, 2001; Nguyen Van Long và Phan Kim Hoang, 2008) đóng vai trò chi phối đối với cấu trúc phân bố của quần xã cá rạn. Kết quả ghi nhận sự khác biệt về quần xã cá rạn giữa các dạng hình thái và cấu trúc rạn trong nghiên cứu này phù hợp với kết quả của Letourneur và cộng sự (2000), Galzin và Legendre (1987).

\section{KẾT LUẬN}

Do tính chất khác biệt về hình thái cấu trúc giữa các kiểu rạn, quần xã cá rạn san hô của kiểu rạn dạng nền (platform) có sự khác biệt so với kiểu rạn dạng riềm nhưng không có sự khác nhau giữa kiểu rạn riềm điển hình và không điển hình. Rạn dạng nền có độ giàu có về loài và mật độ cá thể cao hơn nhiều so với rạn dạng riềm điển hình và không điển hình, trong khi đó các giá trị này lại khá tương đồng giữa rạn riềm điển hình và không điển hình.

Lò̀i cảm on: Nghiên cứu này được thực hiện bởi sự hỗ trợ tài chính của đề tài Giám sát rạn san hô do Total Foundation tài trợ. Tác giả xin cảm ơn những ý kiến đóng góp quý báu của TS. Võ Sĩ Tuấn và PGS.TS. Tore Johan Hoisaeter đối với nghiên cứu này. Cảm ơn sự giúp đỡ nhiệt tình trong công tác thực địa thu thập số liệu của các đồng nghiệp: Phan Kim Hoàng, Hoàng Xuân Bền và Hứa Thái Tuyến. 


\section{TÀI LIỆU THAM KHẢO}

1. Allen G.R., R. Steene, H. Humann and N. Deloach, 2003. Reef Fish Identification Tropical Pacific. New World Publications, Inc., 457pp.

2. Bell J.D. and R. Galzin, 1984. Influence of live coral cover on coral reef fish communities. Marine Ecology Progress Series, 15: 265-274.

3. Beukers J.S. and G.P. Jones, 1997. Habitat complexity modifies the impact of piscivores on a coral reef fish population. Oecologia 114: 50-59.

4. Cadoret L., M. Adjeroud and M. Tsuchiya, 1999. Spatial distribution of chaetodontid fish in coral reefs of the Ryukyu Islands, southern Japan. Journal of Marine Biological Association, UK 79: 725-735.

5. Carcasson R.H., 1977. A field guide to the coral reef fishes of the Indian and West Pacific Ocean. Collins London, 320 pp.

6. Carpenter K.E., R.I. Miclat, V.D. Albaladejo and V.T. Corpuz, 1981. The influence of substrate structure on the local abudance and diversity of Philippine reef fishes. Proceedings of the Fifth International Coral Reef Symposium, Manila 2: 497502.

7. Clarke K.R., 1977. Habitat distribution and species diversity of chaetodontid and pomacentrid fishes near Bimini, Bahamas. Marine Biology 40: 277-289.

8. English S., C. Wilkinson and V. Baker, 1997. Survey Mannual for Tropical Marine Resources. Australian Institute of Marine Science. Towsville, second edition, $390 \mathrm{p}$.

9. Galzin R., 1987. Structure of fish communities of French Polynesian coral reefs. I. Spatial Analysiss. Marine Ecology Progress Series 41: 129 - 136.

10. Galzin R. and P. Legendre, 1987. The fish communities of a coral reef transect. Pacific Science 41: 158-165.

11. Gladfelter W.B. and E.H. Gladfelter, 1978. Fish community structure as a function of habitat structure on West Indian patch reefs. Review. Biol. Trop. 26: 65-84.

12. Harmelin-Vivien M.L, 1977. Ecological distribution of fishes on the outer slope of Tulear reef (Madagascar). Proceedings of 3th International Coral Reef Symposium,1: 289-295.

13. Hodgson G. and S. Waddell, 1998. International Reefcheck Core Method. 
14. Kuiter R.H., 1992. Tropical Reef Fishes of the Western Pacific Indonesia and Adjacent water. Jakarta: PT Granmedia Pustaka Utama, 313 pp.

15. Letourneur Y., 1996a. Dynamics of fish communties on Reunion fringing reefs, Indian Ocean. I. Patterns of spatial distribution. Journal of Experimental Marine Biology and Ecology 195: 1-30.

16. Letourneur Y., M. Kulbicki and P. Labrosse, 2000. Fish stock assessment of the northen New Caledonian lagoons: 1 - Structure and stocks of coral reef fish communities. Aquatic Living Resources 13(2): 65-76.

17. McClanahan T.R. and R. Arthur, 2001. The effect of marine reserves and habitaton population of east African coral reef fishes. Ecological Applications 11: 559-569.

18. Myers R.F., 1991. Micronesian Reef Fishes. A Practical Guide to the Identification of the Coral Reef Fishes of the Tropical Central and Western Pacific. USA: Coral Graphics Production, 298 pp.

19. Nguyen Van Long and Phan Kim Hoang, 2008. Distribution and factors influencing on structure of reef fish communities in Nha Trang Bay Marine Protected Area, South-Central Vietnam. Environmental Biology of Fishes 82: 309324.

20. Randall J.E., G.R. Allen and R.C. Steen, 1990. Fishes of the Great Barrier Reef and Coral Sea. University of Hawaii Press, Honolulu, 506 pp.

21. Steele M.A., 1999. Effects of shelter and predators on reef fishes. Journal of Experimental Marine Biology and Ecology 233: 65-79.

22. Võ Sĩ Tuấn (Chủ biên), Nguyễn Huy Yết và Nguyễn Văn Long, 2005. Rạn san hô biển Việt Nam. NXB Khoa học và Kỹ thuật, 212 trang.

\section{CHANGE OF REEF FISH COMMUNITIES IN DIFFERENT MORPHOLOGIES OF CORAL REEFS}

\section{NGUYEN VAN LONG}

Summary: Change of reef fish communities in different morphologies of coral reefs was conducted at 60 transects of 3 sites of fringing reefs, 3 sites of non-fringing reefs and 3 sites of platform reefs in Ca Na Bay, South-Central Vietnam in 2005 and 2006. Results from cluster analysis and multidimensional scaling performed on data of fish abundance show that 
there was a significant separation of two distinct assemblages of fish communities between platform reefs and fringing reefs $(P<0.01)$, and between platform reefs and non-fringing reefs $(P<0.01)$, but no significant difference was found between fringing reefs and nonfringing reefs $(P>0.05)$. Species richness $\left(25.1\right.$ species $\left./ 100 m^{2}\right)$ and density $(127.0$ inds. $/ 100$ $\left.\mathrm{m}^{2}\right)$ of the platform reefs were much higher than that of fringing reefs $\left(14.4\right.$ species $/ 100 \mathrm{~m}^{2}$ and 94.8 inds. $1100 \mathrm{~m}^{2}$ respectively) and non-fringing reefs (13.2 species $/ 100 \mathrm{~m}^{2}$ and 75.9 inds. 1100 $\left.\mathrm{m}^{2}\right)$, but that were similar between fringing reefs and non-fringing reefs. Value of global correlation coefficient $(R)$ between fringing reefs and non-fringing reefs was very low $(R=$ 0.469) compared to that between platform reefs and fringing reefs $(R=0.897)$, and between platform reefs and non-fringing reefs $(R=0.925)$. This indicates that characteristics of fish communities of fringing reefs were similar to those of non-fringing reefs, but that were different between platform reefs and fringing reefs and non-fringing reefs.

Ngày nhận bài: 04 - 6 - 2009

Ngưòi nhận xét: PGS. TS. Nguyễn Hữu Phụng 